\section{BMJ Global Health}

\title{
Staying afloat: community perspectives on health system resilience in the management of pregnancy and childbirth care during floods in Cambodia
}

\author{
Dell D Saulnier (D , ${ }^{1}$ Hom Hean, ${ }^{2}$ Dawin Thol, ${ }^{2,3}$ Por $I r,{ }^{4}$ Claudia Hanson (D) , ${ }^{1}$ \\ Johan Von Schreeb, ${ }^{1}$ Helle Mölsted Alvesson ${ }^{1}$
}

\begin{abstract}
To cite: Saulnier DD, Hean $\mathrm{H}$, Thol D, et al. Staying afloat: community perspectives on health system resilience in the management of pregnancy and childbirth care during floods in Cambodia. BMJ Global Health 2020;5:e002272. doi:10.1136/ bmjgh-2019-002272
\end{abstract}

Handling editor Stephanie M Topp

- Additional material is published online only. To view, please visit the journal online (http://dx.doi.org/10.1136/ bmjgh-2019-002272).

Received 23 December 2019 Revised 27 February 2020 Accepted 30 March 2020

Check for updates

\section{(C) Author(s) (or their} employer(s)) 2020. Re-use permitted under CC BY-NC. No commercial re-use. See rights and permissions. Published by BMJ.

${ }^{1}$ Department of Global Public Health, Karolinska Institutet, Stockholm, Sweden ${ }^{2}$ School of Public Health, National Institute of Public Health, Phnom Penh, Cambodia ${ }^{3}$ Department of Preventive Medicine, Phnom Penh, Cambodia

${ }^{4}$ Technical Bureau, National Institute of Public Health, Phnom Penh, Cambodia

Correspondence to Dell D Saulnier; dell.saulnier@ki.se

\section{ABSTRACT}

Introduction Resilient health systems have the capacity to continue providing health services to meet the community's diverse health needs following floods. This capacity is related to how the community manages its own health needs and the community and health system's joined capacities for resilience. Yet little is known about how community participation influences health systems resilience. The purpose of this study was to understand how community management of pregnancy and childbirth care during floods is contributing to the system's capacity to absorb, adapt or transform as viewed through a framework on health systems resilience.

Methods Eight focus group discussions and 17 semistructured interviews were conducted with community members and leaders who experienced pregnancy or childbirth during recent flooding in rural Cambodia. The data were analysed by thematic analysis and discussed in relation to the resilience framework.

Results The theme 'Responsible for the status quo' reflected the community's responsibility to find ways to manage pregnancy and childbirth care, when neither the expectations of the health system nor the available benefits changed during floods. The theme was informed by notions on: i) developmental changes, the unpredictable nature of floods and limited support for managing care, ii) how information promoted by the public health system led to a limited decision-making space for pregnancy and childbirth care, iii) a desire for security during floods that outweighed mistrust in the public health system and iv) the limits to the coping strategies that the community prepared in case of flooding. Conclusions The community mainly employed absorptive strategies to manage their care during floods, relieving the burden on the health system, yet restricted support and decision-making may risk their capacity. Further involvement in decision-making for care could help improve the health system's resilience by creating room for the community to adapt and transform when experiencing floods.

\section{INTRODUCTION}

Floods are the most common type of weatherrelated disaster, affecting $>34$ million people globally and billion dollar economic losses

\section{Key questions}

What is already known?

- Resilient health systems can continue to provide health services to meet the variety of health needs seen during floods, a type of shock to health systems.

- They are able to manage shocks by absorbing them using existing strategies and resources, adapting to them by adjusting how resources are used or transforming the structure of the system to avoid shocks.

- The capacity to absorb, adapt or transform is related to how the community copes with health needs and their interactions with the health system, yet how their actions can influence resilience is not yet well described.

What are the new findings?

- The communities in this study mostly employed strategies to absorb the initial shock of floods, leaving them open to risk or a failure to cope if a more extreme flood or different shock occurs.

- The described dependence on absorptive rather than adaptive or transformative capacity can be linked to limited involvement in decision-making for care, a lack of ownership in the health system and a power imbalance between the community and the health system.

\section{What do the new findings imply?}

- Greater involvement in decision-making at the local level could create a more acceptable and efficient health system response to shocks, bolstering the community's capacity to adapt and transform and thus helping to build health systems resilience.

in 2018. ${ }^{1}$ If global warming continues at its current pace, the number of floods per year is expected to increase worldwide. ${ }^{2}$ Floods are not always disasters, but repeated seasonal flooding and less frequent occasional floods are still damaging and deplete economic and developmental resources. ${ }^{3}$

A resilient health system has the capacity to continue providing health services when 


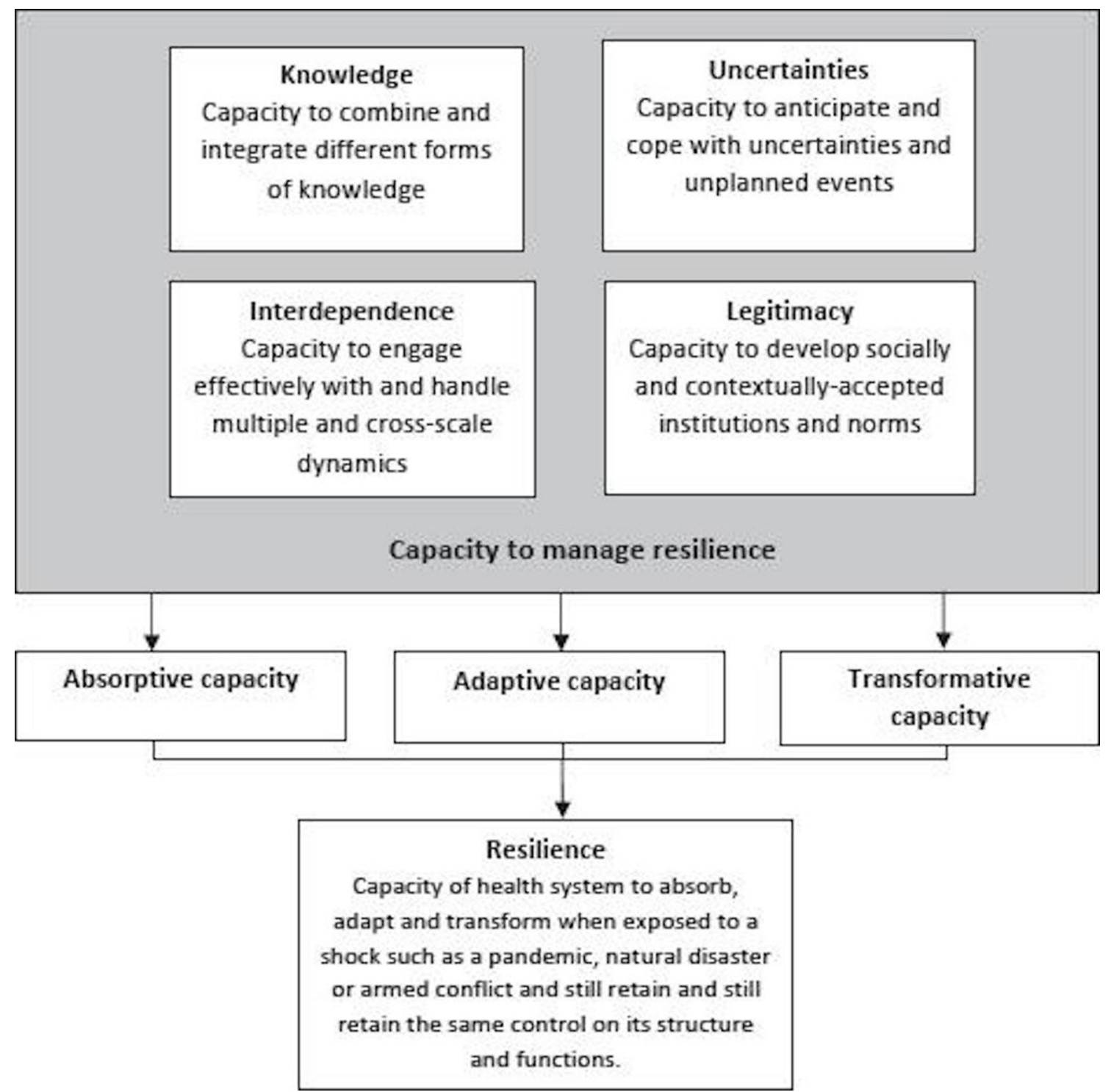

Figure 1 The dimensions of resilience governance framework by Blanchet et al. ${ }^{10}$

shocked, for both new health needs caused by the shock and routine health needs. ${ }^{4-6}$ Floods are a typical example of a shock to this capacity. ${ }^{7-9}$ The Dimensions of Resilience Governance framework (figure 1) posits that if a health system is able to integrate and process knowledge, anticipate and cope with uncertainty, manage interactions with other systems at multiple levels (interdependence) and create a socially and contextually accepted system (legitimacy), it is then capable of managing shocks. ${ }^{10}$ This is done by absorbing shocks like floods using existing strategies and resources, adapting to them by temporarily adjusting how resources are used or transforming the structure of the system in the long-term to avoid shocks. ${ }^{11-13}$

Strengthening absorptive, adaptive and transformative capacities can make a system less vulnerable to shocks. This can be achieved through a variety of actions and means that are dependent on the system's context and governance, the implicit and explicit rules that guide the relationships, decisions and actions among people and groups in the health system. ${ }^{51214-16}$ The strength of the health system's capacities depends in part on the dynamics between actors inside and outside the health system, such as policymakers and the population it serves..$^{10} 17$ People living in affected communities use formal health services and employ their own strategies and resources to meet their health needs. For instance, trust affects their utilisation of services, interactions with the system and ultimately the system's ability to withstand shocks. ${ }^{18} 19$ Involving the population was essential to containing the West Africa Ebola outbreak, but difficult relationships between the population and health systems led to avoidance of formal health services, affecting both the population's health and the health system's response. ${ }^{520-22}$ How the community copes with new and routine health needs during floods indicates both the extent that the health system is meeting their needs and the community and health system's joined capacities for resilience. ${ }^{418}$

The literature has called for a better understanding of how the community's capacity to manage their health needs during shocks influences health systems 
resilience. ${ }^{5}{ }^{21} 23-25$ Although developed to analyse the supply side of the health system, we apply the Dimensions of Resilience Governance framework to the community's capacity because of its focus on the interactions that create the capacity to manage resilience. The aim of this study was to understand how the actions of the community and their interactions with the health system during seasonal and occasional floods in Cambodia are contributing to the system's capacity to absorb, adapt or transform, viewed through the framework. Although neither pregnancy nor childbirth or emergency pregnancy complications are causally linked to floods, they are typical routine and new health needs and can be used to indicate a health system's ability to cover other new and routine health needs after a shock. Pregnancy is representative of routine health needs that do not change because of floods but still require preventive and promotive care that can be planned in advance, while deliveries and complications are representative of new health needs that can emerge during floods, occur suddenly or unexpectedly and require skilled management and emergency care. ${ }^{26}{ }^{27}$ The research question was: how do community members manage care for pregnancy and childbirth during seasonal and occasional floods in rural Cambodia? A concurrent study on antenatal and childbirth service provision and management during floods from the health worker perspective is in manuscript. ${ }^{28}$

\section{METHODS}

\section{Study setting}

This is a qualitative study of community perspectives on health system resilience in two rural operational districts in Cambodia. It is a majority Buddhist and Khmer ethnicity country of approximately 15 million, with about $80 \%$ living in rural areas. ${ }^{29}{ }^{30}$ It has undergone rapid economic growth and became a lower middle-income country in 2016. Between 2000 and 2015, life expectancy rose from 58.4 to 68.6 years, and maternal mortality fell from 484 deaths to 161 deaths per 100000 live births. ${ }^{31}$ Cambodia is exposed to river pulse floods in some provinces every year, while other provinces occasionally flood from monsoon rains, and climate change is expected to increase flooding. ${ }^{32} 33$ These floods can be unexpectedly severe, like the 2011 and 2013 flood disasters that affected over a million people. ${ }^{3435}$

Social and political decision making in Cambodia is underpinned by hierarchical relationships. ${ }^{36}{ }^{37}$ Individuals belong to a geographically close, extended family network, headed by the eldest relatives. Within villages, wealthier, better connected families can act as patrons to less powerful, poorer families. ${ }^{37} 38$ The village chief is the social and administrative leader of the village, responsible for the order and well-being of the village. In turn, villages are overseen by an elected commune chief and commune council members.

Public health centres and private clinics provide routine antenatal care and care for uncomplicated deliveries ${ }^{39}$ and private and district referral hospitals provide additional antenatal services and emergency obstetric care. ${ }^{40}$ Village health support groups link villages to public health centres and provide maternal health education, referrals to health facilities and track pregnancies and births. $^{41}$

\section{Study design, participant selection and access}

The two study districts were selected because of their exposure to floods: one district floods seasonally (every year) and the other floods occasionally (every few years).$^{42}$ The study used flood terminology developed from and contextualised for the districts and villages. In the seasonally flooded district, the terms 'small water' (floods land around the village but does not flood major roads) and 'big water' (floods land in the village and roads so that travel requires a boat) were used. In the occasionally flooded district, there was no communal definition of flooding. Water became a flood when it damaged rice fields or covered village roads. Floods lasted for a few days up to 3 months in the districts.

The study was conducted in eight villages using a structured enrolment (figure 2). ${ }^{43}$ We first introduced the study to the two provincial and district health departments and discussed the history of flooding in the districts. We then visited the five health centres in the districts that had flooded most recently and repeated the process to produce a list of recently flooded villages in their catchment areas. The villages were visited and enrolled if flooding was confirmed by the village leaders using local terminology. All villages experienced flooding in the past 6 months (table 1 ).

Participants were purposively selected to create a heterogeneous sample of gender-based and age-based perspectives on managing pregnancy and childbirth during floods. Focus group discussions (FGDs) were conducted with women 18 years or older who were pregnant or delivered during the most recent flood, or men whose partner met the same criteria. Semi-structured interviews were conducted with village chiefs, village health support groups, traditional birth attendants (TBAs), paternal or maternal grandmothers and commune administrators, all of whom were expected to have experience with maternal health needs or contact with pregnant women during floods. Eligible men and women were identified by health centre staff from the vaccination and antenatal care books at the health centre, using the dates of the floods in the village. Village chiefs and village health support groups identified additional men and women who were not on the health centre lists, the TBAs, grandmothers and commune members, and approached all participants to take part.

\section{Data collection}

Two female data collectors with qualitative research experience, a younger Cambodian midwife and current Master's student in public health (author $\mathrm{HH}$ ), and an 


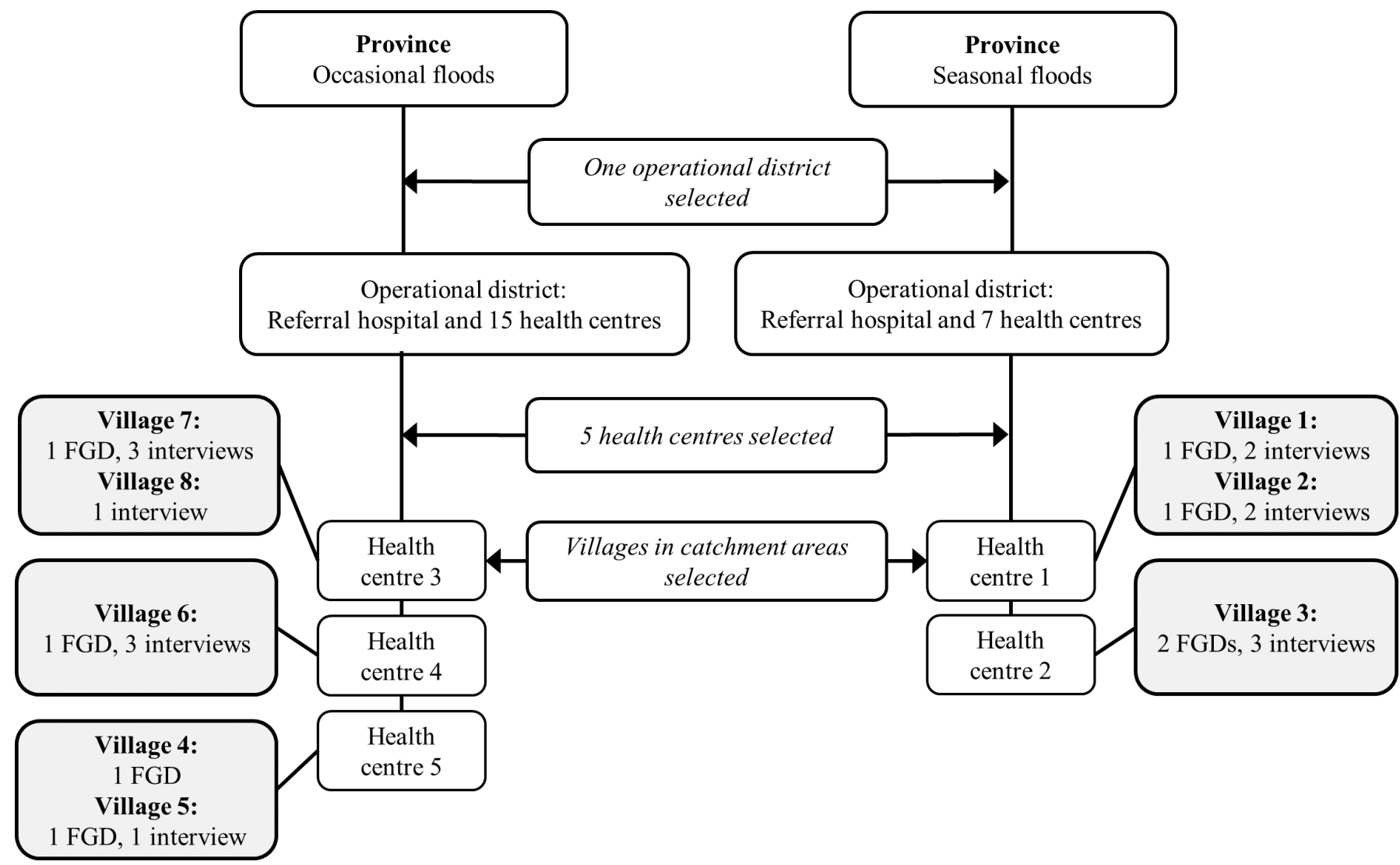

Figure 2 Study site selection and data collection per village. FGD, focus group discussion.

older Cambodian medical doctor, collected data between November and December 2018. We conducted and audiorecorded 17 semi-structured interviews and 8 FGDs in Khmer at the end of the rainy season (table 2). The FGDs had 4-7 participants (41 participants in total) and lasted $60-85 \mathrm{~min}$, while the interviews lasted between 48 and
$92 \mathrm{~min}$. None of the participants knew the data collectors, and the interviews were held in private, neutral, communal spaces such as the temple, local school or participant's home. The authors DDS and DT informally interviewed additional community members to triangulate the data during the field work.

\section{Table 1 Characteristics of the eight selected villages}

\begin{tabular}{|c|c|c|c|c|c|}
\hline \multirow[b]{2}{*}{ Village } & \multirow{2}{*}{$\begin{array}{l}\text { Type of } \\
\text { flooding }\end{array}$} & \multirow{2}{*}{$\begin{array}{l}\text { Approximate } \\
\text { number of } \\
\text { households }\end{array}$} & \multicolumn{2}{|c|}{$\begin{array}{l}\% \text { poor } \\
\text { households* }\end{array}$} & \multirow[b]{2}{*}{ Most recent flood } \\
\hline & & & Level 1 & Level 2 & \\
\hline 1 & Seasonal & 175 & 15.6 & 19.0 & $\begin{array}{l}\text { August to October. Roads and rice fields flooded, livestock } \\
\text { evacuated. }\end{array}$ \\
\hline 2 & Seasonal & 200 & 4.7 & 16.0 & $\begin{array}{l}\text { August to October. Roads and rice fields flooded, one house } \\
\text { destroyed. }\end{array}$ \\
\hline 3 & Seasonal & 275 & 1.0 & 18.6 & June to August. Roads flooded. \\
\hline 4 & Occasional & 100 & 15.3 & 22.1 & $\begin{array}{l}\text { August to October. Roads and rice fields flooded, four houses } \\
\text { destroyed. }\end{array}$ \\
\hline 5 & Occasional & 50 & 30.9 & 19.8 & $\begin{array}{l}\text { July to October. Roads and rice fields flooded, six or seven } \\
\text { houses destroyed. }\end{array}$ \\
\hline 6 & Occasional & 850 & 4.0 & 6.6 & $\begin{array}{l}\text { July to August. Only flooded one area of village. Rice fields } \\
\text { flooded, 20-30 houses destroyed. }\end{array}$ \\
\hline 7 & Occasional & 250 & 1.8 & 4.9 & $\begin{array}{l}\text { August to October. Roads and rice fields flooded, } 50-60 \text { houses } \\
\text { affected. }\end{array}$ \\
\hline 8 & Occasional & 225 & 5.0 & 7.5 & October. Rice fields flooded. \\
\hline
\end{tabular}

${ }^{*}$ According to the IDPoor poverty identification programme in $2014 .{ }^{57}$ Poor level 1 are the poorest households, poor level 2 are poor households; the remaining percentage of households have average or better off living conditions. 
Table 2 Characteristics of the participants

\begin{tabular}{|c|c|c|c|c|c|c|}
\hline Source & Type of flooding & Gender & $\begin{array}{l}\text { Age range } \\
\text { (years) }\end{array}$ & $\begin{array}{l}\text { Number of } \\
\text { children }\end{array}$ & $\begin{array}{l}\text { Formal } \\
\text { education } \\
\text { (years) }\end{array}$ & Occupation(s) \\
\hline FGD 1 & Seasonal & Women & $29-40$ & At least 1 & $0-6$ & Rice farming, caretaker. \\
\hline FGD 2 & Seasonal & Men & $25-39$ & $1-4$ & Unknown & Rice farming, fishing, glass cutting. \\
\hline FGD 3 & Seasonal & Women & $20-36$ & $1-3$ & $0-5$ & Rice farming, caretaker. \\
\hline FGD 4 & Seasonal & Men & $26-38$ & $1-6$ & $0-5$ & $\begin{array}{l}\text { Rice farming, farm worker, fishing, } \\
\text { construction worker. }\end{array}$ \\
\hline FGD 5 & Occasional & Men & $25-37$ & $1-5$ & Unknown & Rice farming, merchant, mechanic. \\
\hline FGD 6 & Occasional & Women & $18-30$ & $1-5$ & $0-8$ & $\begin{array}{l}\text { Rice farming, raising livestock, } \\
\text { farm worker, caretaker. }\end{array}$ \\
\hline FGD 7 & Occasional & Women & $18-33$ & $1-3$ & $2-10$ & $\begin{array}{l}\text { Rice farming, raising livestock, } \\
\text { farm worker, casino worker. }\end{array}$ \\
\hline $\begin{array}{l}\text { Three } \\
\text { interviews }\end{array}$ & $\begin{array}{l}\text { One seasonal } \\
\text { Two occasional }\end{array}$ & TBAs & & Three women & $67-79$ & $\begin{array}{l}\text { Informal antenatal and childbirth } \\
\text { care. }\end{array}$ \\
\hline $\begin{array}{l}\text { Four } \\
\text { interviews }\end{array}$ & $\begin{array}{l}\text { Two seasonal } \\
\text { Two occasional }\end{array}$ & \multicolumn{2}{|c|}{ Village chiefs } & Four men & $46-54$ & $\begin{array}{l}\text { Responsible for village health } \\
\text { administration, benefits and } \\
\text { support programmes; reporting } \\
\text { health data; resolving complaints } \\
\text { about health services; providing } \\
\text { emergency support during floods. }\end{array}$ \\
\hline $\begin{array}{l}\text { Five } \\
\text { interviews }\end{array}$ & $\begin{array}{l}\text { Two seasonal } \\
\text { Three occasional }\end{array}$ & \multicolumn{2}{|c|}{$\begin{array}{l}\text { Village health support } \\
\text { group workers }\end{array}$} & $\begin{array}{l}\text { Two women } \\
\text { Three men }\end{array}$ & $40-62$ & $\begin{array}{l}\text { Responsible for health education } \\
\text { and promotion; assisting village } \\
\text { chief with health administration. }\end{array}$ \\
\hline
\end{tabular}

FGD, focus group discussion.

Topic guides were informed by the Dimensions of Resilience Governance framework (online supplementary annex 1). The four theoretical dimensions were adapted into concrete questions about participants' experience with managing maternal health needs during floods. The guides were adjusted during piloting and after discussions between the data collectors and first author during data collection, as relevant topics were raised. The concept of information power structured the data collection. ${ }^{44}$ Three interviews were added after appraising the power of the data during collection. All interviews and FGDs were transcribed verbatim into Khmer, then translated into English by one Cambodian translator. Uncertainties during translation were discussed with the data collectors and the first author.

\section{Data analysis}

We performed a data-driven thematic analysis ${ }^{45}$ in NVivo V.12 Pro, led by the first author (DDS) with frequent input from the coauthors. DDS developed a list of codes that reflected descriptions or ideas about managing health needs during floods identified in the data. Codes and ideas were checked across the different characteristics of the data. Salient issues like information sharing were compared and contrasted between seasonally and occasionally flooded villages, antenatal and childbirth care, village leaders and community members and between FGDs and interviews. After coding the first five interviews, codes were discussed with the last author and revised, and then regularly revised together for the remainder of the analysis. After coding, we reviewed the data using the resilience framework's concepts of knowledge, interdependence, uncertainty and legitimacy ${ }^{10}$ and explored how they influenced the relationships between codes. The subcategories and categories were then created from observed patterns of meaning in the data plus the theoretical understanding gained during the 
Table 3 Theme, categories and subcategories describing how community members manage pregnancy and childbirth care needs during floods

\begin{tabular}{|c|c|c|}
\hline Theme & Categories & Subcategories \\
\hline \multirow[t]{4}{*}{$\begin{array}{l}\text { Responsible for } \\
\text { the status quo }\end{array}$} & Depending on others but ready to be alone & $\begin{array}{l}\text { Communities gaining and losing solutions for pregnancy care. } \\
\text { Help from others is not guaranteed during floods. }\end{array}$ \\
\hline & $\begin{array}{l}\text { Women navigating a shrinking space for choices } \\
\text { about care }\end{array}$ & $\begin{array}{l}\text { One right choice. } \\
\text { Searching for control over care within their community. }\end{array}$ \\
\hline & $\begin{array}{l}\text { A personal trade-off between mistrust and the } \\
\text { benefits of formal care }\end{array}$ & $\begin{array}{l}\text { Balancing fear with mistrust. } \\
\text { Seeking health security during pregnancy. }\end{array}$ \\
\hline & Mitigating difficulty during floods & $\begin{array}{l}\text { The boundaries of coping. } \\
\text { Prepare to cope during floods. }\end{array}$ \\
\hline
\end{tabular}

previous step. From here, a single theme was identified that captured the meaning and association between the categories as a whole. Lastly, the findings were mapped back onto the framework to show their contributions to the four dimensions and absorptive, adaptive, and transformative capacities.

\section{Ethical considerations}

The health departments, commune and village chiefs and health centres granted permission to conduct the study. All participants gave written or verbal consent prior to taking part. Participants who felt uncomfortable or emotional discussing their coping strategies or childbirth and flood experiences were reminded of their right to withdraw; none opted to stop participating.

\section{Patient and public involvement}

The research was done without public involvement.

\section{RESULTS}

We identified the overarching theme Responsible for the status quo with four categories (table 3). It captures the responsibility placed on the community to find their own strategies to continue managing pregnancy and childbirth care during floods, while locked in rigid relationships with the public health system and village leaders where they give up power and preferences for the benefits of care.

\section{'Depending on others but ready to be alone'}

The category describes how community members live within a continuously changing context that is worsened by difficult and unpredictable floods, and where help is limited.

\section{Communities gaining and losing solutions for pregnancy care}

Community members described contextual changes over time in the community and the health system, including beneficial changes in multiple spheres: (i) better roads for easier travel to health facilities, (ii) mobile phones and social media that facilitated communication with providers, (iii) less poverty increasing their ability to pay for care and (iv) a growing private healthcare sector increasing options for care. Pregnancy care shifted from being primarily managed by traditional medicine and traditional, unlicensed midwives to facility-based care by licensed providers.

While the diverse developmental and economic changes were generally expressed as positive and transformed their ability to stay healthy during floods, participants raised concerns about losing community-based skills for pregnancy and childbirth and the need to rely on formal care during floods. Negative changes were those that affected their options for home-based healthcare, such as losing TBAs as a resource:

Frankly speaking, back then there was a grandma who did it [delivered babies at home] but she passed away five years ago. So, there's no one that can help us now but doctors. They are the only hope we have. (Village health support group worker, interview 10)

\section{Help from others is not guaranteed during floods}

Despite flood warnings, floods were described as difficult and unpredictable situations that exacerbated existing challenges for care. Floods were seen as inevitable natural phenomena but living through them felt overwhelming, particularly in the seasonally flooded villages. Community members talked about needing to depend on themselves during floods:

It's hard to ask them (other villagers) because we can only ask for help one or two times. What if someday they don't have anything either? If we ask them too often, we might be troublesome to them, so we have to accept that. (FGD 1 , women)

The sense that individuals were responsible for absorbing the impact of floods was echoed by others. They relied on family and social goodwill during floods, without expectation, since the whole community was affected.

Men and women expected they would need to solve problems themselves and were concerned about knowing who to ask for help and how to find reliable care. Floods exacerbated existing problems with the reliability of health services at health centres in general, as described by a father in an example of unreliable staffing at a public health centre in the seasonally flooded district during floods: 
They would be even more late (during floods). I took my child for vaccination. They were not there. I waited so long that I went back home before they arrived. Like I said, it's not easy to commute during floods. (FGD 2, men)

The quote highlight showing the entire community, including providers, is affected by floods that can limit available help.

'Women navigating a shrinking space for choices about care' The category represents how the information promoted by the public health system has led to a decision-making space where community members felt powerless when navigating the choices involved with pregnancy care.

\section{One right choice}

As a routine measure, village chiefs, commune chiefs, the health centres and village health support group workers repeatedly informed pregnant women to seek regular antenatal care and deliver at a facility. Men and women were made aware of $i$ ) the health risks of not receiving facility-based care (preferably at public facilities), ii) the legal consequences to TBAs if they provided antenatal or childbirth care and iii) the risk of exclusion from patronage relationships. The message was regularly reinforced by village leaders and healthcare providers:

We can encourage them to go have their prenatal care. I advise them both in and outside the meeting. When I see them, I tell them at their house. (Village chief, interview 8)

Men and women felt their behaviour was scrutinised, and expressed a sense that they 'must' get facility-based care, even during floods, that was echoed by village leaders:

Yes, we must go. In short, we have to go and get a check-up every month. The doctor will check us and tell us when to go next month. We have to go regularly. (You) cannot miss this, it's a must that pregnant women go there. (FGD 4, men)

They don't dare to (deliver at home). And the (traditional) midwife also doesn't dare to either. (Village health support group worker, interview 6)

Health providers were described as holding a large amount of decision-making power, such as deciding whether to see patients or not, what patient behaviour was appropriate, whether to accept or reject informal payments and in some cases, whether to charge service fees. Women and men attempted to exert some control over their care by making decisions available to them within their realm, for example, refusing traditional medicine offered to them by parents or elders, choosing to deliver at the hospital to avoid referral from the health centre or using 'fast labour' as shorthand for deciding to deliver at home under plausible circumstances.

\section{Searching for control over care within their community}

Participants described a variety of social and economic resources that were possible to activate during floods, such as borrowing or renting transport, taking loans from family members and neighbours, buying their own boat or private care for the wealthier. Although anxious about the consequences of seeking out a TBAs, men and women considered them trusted village resources who were able to reassure them about their pregnancies, influence them to seek formal care and advocate on their behalf to the public health system:

The (traditional) midwife is like the village keeper; she can't be skipped. She will sleep and look after us and help facilitate. You can wake her up anytime. She will help to get you to the hospital. She will sleep and wait until morning then she will go back. (FGD 4, men)

Alternatively, village chiefs were seen as gatekeepers to further help during floods. In their role as village heads, they linked the village to other sectors (eg, benefit schemes) and levels of administration (eg, district chiefs). They were described as a powerful option for help with either antenatal or childbirth care, for example, by calling doctors on the woman's behalf, to be used if other resources failed:

Unless she has no relatives, then she would come to ask for help. Even if she has little money, I help as much as possible. (Village chief, interview 5)

Women and men expressed a feeling of entitlement to help from village chiefs, that was reinforced by chiefs as part of their obligation to the village and to those above them in the social and administrative hierarchy.

\section{'A personal trade-off between mistrust and the benefits of formal care'}

The category denotes how community members' misgivings about care from the public health system is exchanged for their desire to feel secure during floods by seeking formal antenatal and childbirth care.

\section{Balancing fear with mistrust}

Floods were discussed as an uncertain time to be pregnant. Community members worried about birth and emergency complications because of their unpredictability and subsequent difficulty in travelling and getting help during floods, and a general awareness of the potential risks to health if they did not receive formal care. They were most afraid of delivering at home, without access to medical help and unable to travel to a facility:

If we do not go then it could be very risky for us. Sometimes, (women) have the pain in the night. And there's no one to take them there because the flood was here all around, there's no boat or anything at all. It's risky (life threatening). (FGD 3, women)

As a result, they described a desire for the benefits of formal antenatal and childbirth care, such as reassurance about the health of the baby and pregnancy advice from providers. On the other hand, they expressed frustration with the quality of care they did receive from public facilities, like dissatisfaction with the content of health 
outreach during floods, feeling shamed by providers and frustration with their behaviour, attitude and absenteeism:

(The midwife) came but we had to wait for a long time. I don't want to say this, but this health center is called 'the ghost health center' because whoever goes there never gets to see them (the staff) immediately. We have to wait. (FGD 2 , men)

\section{Seeking health security during pregnancy}

Pregnancy was described as a time for more security, and floods exacerbated this need. Specific adaptations to safeguard pregnancy were: i) men staying home from work in the days or weeks before the baby was due, ii) men and the extended family taking over household chores before and after childbirth, especially during floods and iii) abstaining from travel during pregnancy. Participants noted that public facilities continued to deliver maternal health services during floods despite staff shortages. They also identified antenatal and childbirth care as different from other care and were willing to trust it more than other services:

I took my daughter to deliver at the (referral) hospital, our midwives were so attentive to us. But if it's other diseases, it's hard. It's hard because they lack medicine. They always lack medicine so then the people have to find the medicine outside. (Village chief, interview 7)

\section{'Mitigating difficulty during floods'}

The category explains how the community has learnt to prepare for and cope with pregnancy during floods through experience and shared knowledge yet is not able to negate the challenges during floods.

\section{Preparing to cope during floods}

Participants learnt to cope by living through floods and women inherited pregnancy knowledge from older generations. In the seasonally flooded villages, they implemented short-term strategies like stockpiling food and supplies, preparing transport, preparing a clean water source and saving money, and long-term strategies like raising the level of their land. In the occasionally flooded villages, community members discussed feeling less ready to cope with floods and unsure how to prepare:

On my side, there are not floods so often so I don't know what to prepare at all. (FGD 6, women)

Routine preparations for pregnancy included i) transport and gasoline, ii) a companion for care visits, iii) knowledge of their delivery date and iv) money for formal and informal fees. During floods, additional knowledge and resources were needed to adapt to the changing circumstances, such as saving money for the additional cost of the ferry boat and allocating extra time to seek antenatal care in the seasonally flooded villages. Whether they had experienced one flood or many, they described preparation as key when facing the uncertainty of floods:
For me, it's important to prepare during pregnancy since we cannot predict what problems we're going to have. We have to be ready and inform our family about the due date. (FGD 3, women)

\section{The boundaries of coping}

Community member needed to decide how to care for their pregnancy when regular strategies no longer worked during floods. Secondary strategies used included: i) choosing where to get care by picking the easiest road to travel in the occasionally flooded district, ii) going into debt for care when money was short during floods, iii) temporarily living at the health centre before their due date to avoid travelling while in labour and iv) skipping or delaying antenatal care if they were unable to afford it, unable to travel easily or felt well enough to avoid the hassle of going; this strategy was more often reported in the seasonally flooded district.

Women tended to find congruence with what those around them wanted, such as following pregnancy advice from their peers. Decisions about where to get antenatal care or deliver were mostly made between the couple or with immediate family, although women were ultimately expected to do as the family decided. This was articulated by men as an active choice to take control of the situation, and by women as letting someone else take control:

I just told my wife that we would go to (health center), then we just went there, at 1 am. (FGD 8, men)

When I had the pain, they just took me there and I didn't know anything about it. I followed them wherever they took me. (FGD 6, women)

The pressure to conform to the wants of those around the women limited the decisions they could make about care for their pregnancy even further.

Figure 3 visualises the findings as they relate to the Dimensions of Resilience Governance framework. ${ }^{11}$ It shows how the interactions and relationship between the community and the health system during floods are interlinked with the framework's four dimensions and have led to different absorptive, adaptive and transformative capacities. From the community perspective, static support during floods meant they needed to cope with uncertainty and find absorptive and adaptive strategies for care, anchored in knowledge and experience. System changes embedded in the context and powerful expectations about care were received from the top-down, challenging the legitimacy of the system while simultaneously necessitating adaptation and creating some transformation.

\section{DISCUSSION}

Our qualitative study exploring the community response to pregnancy and childbirth care during seasonal and occasional floods revealed the community's capacity to absorb the flooding, while recognising there was less capacity for adaptive and transformative processes. This 


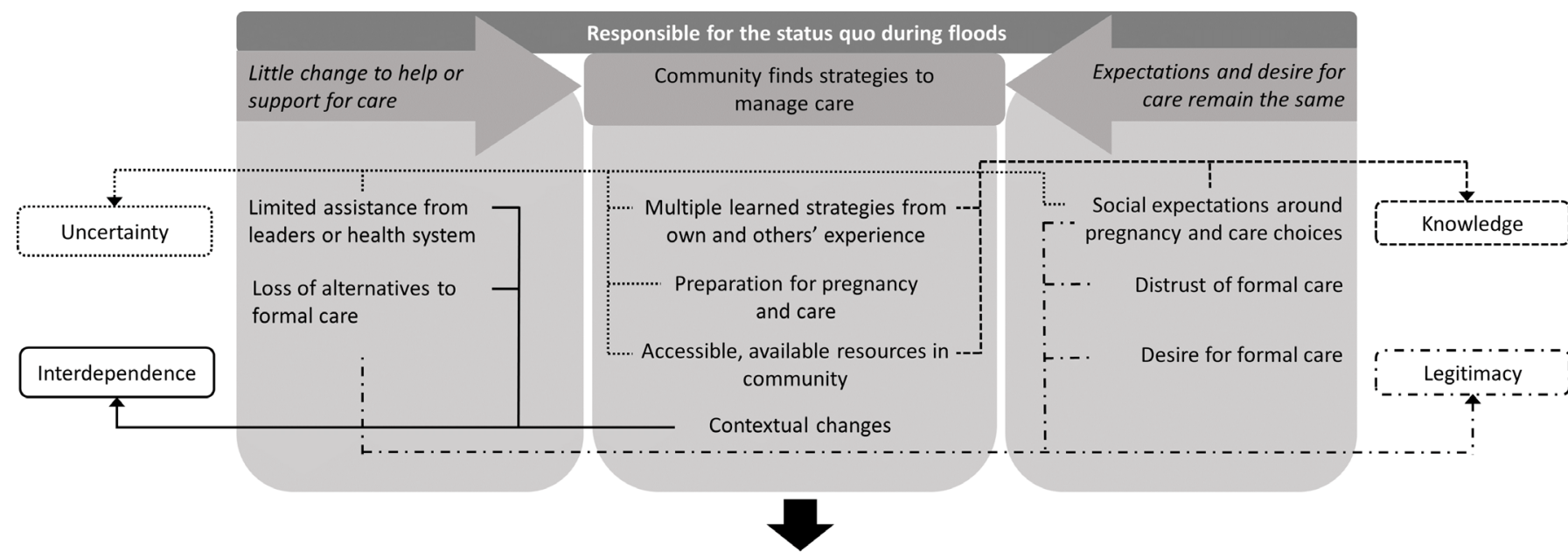

\section{Absorb}

Using tangible and intangible resources to receive help and use care

Employing a range of primary and secondary strategies

Making socially acceptable decisions about care

\section{Adapt}

Change of social roles during pregnancy Using experience, knowledge to prepare for floods

Losing options for home-based care

Figure 3 Representation of the findings as they contribute to the four dimensions of resilience governance and lead to the community's capacity to absorb, adapt or transform during floods. ${ }^{11}$

capacity weakness can be linked to the narrow avenues for decision making and ownership in the system described by the participants. Information sharing appeared as a mostly one-way, top-down process from the health system to community members, and community members lacked the power to advocate for their preferred care. Although the community was able to manage their health needs during floods, the ostensible lack of involvement in decision-making may be putting their capability at risk.

From the community's perspective, the health system's response to health needs during floods changed little, and the community mainly absorbed the initial shock of floods. Adaptive capacity appeared less robust and more related to managing pregnancy than floods in the occasionally flooded district. Maternal health services were continually available during floods, according to participants, suggesting absorption by the health services as well. Investment in adaptive or transformative measures over time by the health system to relieve the responsibility on the community was not described, leaving the community vulnerable to more severe floods and different shocks, should their absorptive and adaptive capacities fail. ${ }^{46}$ However, determining where one capacity stops and another starts proved difficult. For instance, the 2012 health system policy that limited the use of TBAs ${ }^{47}$ may have been transformative for the public health system as a whole, but likely created some of the need for absorptive and adaptive capacity at the community level seen in this study while compromising trust in the system.

The finding that the community mainly absorbed flood shocks may be due to the comparatively low intensity of the 2018 floods when compared with earlier disasters. Floods were described as a repeated stressor in both districts rather than an acute shock, supporting the idea that the degree of change needed to manage a shock is relative to the intensity and length of the shock. ${ }^{12} 4849$ However, this view can mask the interdependence between the health system and the other complex systems in the context. ${ }^{50}$ Participants in both districts routinely compared recent floods to the flood disaster in 2000. Yet Cambodia has undergone drastic and rapid developmental, political and economic changes in 20 years, many of which were raised as reasons for why it was now easier to care for health during floods. What is currently viewed by us as the capacity to absorb and adapt to floods may in fact be the byproduct of transformative change in multiple other systems in the past few decades, as was noted in recent studies of health financing mechanisms and village malaria workers in Cambodia. ${ }^{3851}$

In this study, the one-way flow of information between the community and the health services inhibited the actions and decisions that community members felt they could take, potentially reducing their influence on the system and system's legitimacy. ${ }^{552}$ With a small margin to make decisions of their own and a shift to facility-based care, individual and community-based knowledge about pregnancy and childbirth could be losing its relevance. Although the uptake of facility-based care has likely helped to improve maternal health outcomes, ${ }^{53}$ it may be a weakness of the system if the community and health system are exposed to shocks that do disrupt health services, and alternative strategies of coping with health needs have been lost. For instance, community members often preferred to use TBAs for reassurance about their health during floods but did not have the power to advocate for their use. Awareness of why these preferences persist and how it affects decisions about care during floods can help in understanding the limits of community 
coping, trust and involvement in governance that may have implications during other shocks.

Linked to the above, we found that demand for formal care still exists during floods, but with limited trust in the services. The restricted power of the communities meant they lost the option to make preferred, alternative choices about their care during floods, and as a result, their sense of ownership and trust in the system. Trust and ownership are directly related to the community's involvement in governance, affecting their interactions with the health system and ultimately the system's ability to withstand shocks. ${ }^{51018}$ Other studies from Cambodia have found a similar reluctance to take part in formal care out of mistrust or to regain control over health-related decisions. ${ }^{54-56}$ However, maternal health services were seen as different and more trustworthy than other care. Major investments and reforms have improved maternal health services, ${ }^{5758}$ more so than other services. ${ }^{59}$ This has likely had an influence on the community's trust in the services, with implications for the private sector. The private sector dominates non-maternal health service uptake, and remains mostly unregulated and unintegrated with the public sector. ${ }^{5860} 61$ Disentangling the reasons for trust in private versus public sector care could give insight to the current and future role of the private sector in responding to flooding.

Strengths of the study include triangulation of methods with formal and informal interviews field notes, and the diversity in types of participants across village and administrative levels. An additional strength was using interviewers who were familiar with maternal health services in the rural context, but within a diverse research team from multiple disciplines and range of local and global experiences with maternal health and resilience. To help prevent the data collectors' clinical backgrounds from influencing the discussions, they presented themselves as researchers rather than clinicians. We felt the final sample size created high information power through the strong dialogue and applied theory, in combination with a well-defined aim, cross-case analysis, and sparse sample specificity.

Limitations included difficulty in enrolling FGD participants because of small village size, the timing of data collection during harvest season and migration during pregnancy, likely affecting the range of ages and economic backgrounds captured. This was ameliorated by asking village chiefs and village health support group workers to help identify eligible participants and enrolling a neighbouring village if necessary. We broadly refer to participants as community members, recognising that living in the same village does not equate to living in communion. We worked to include an heterogenous participant mix and to understand relationships between men and women, village leaders and providers when managing care during floods. ${ }^{25}$ Separating the participants' thoughts on pregnancy and childbirth during floods from their 'baseline' experiences in non-flood times proved difficult, as floods do not explain all of the challenges and strategies raised by the community. All FGDs and interviews started with a discussion in the local terminology of the recent floods that the participants experienced, and the data collectors structured the discussions around these events. The conceptual nature of the framework meant that a certain level of abstraction from the data was necessary during analysis. We dealt with this by using a data-driven approach during coding and then allowed the categories and themes to be influenced by the framework.

The framework was useful for outlining the community's capacity to manage resilience. However, we observed few empirical differences in results between the seasonally and occasionally flooded districts, which suggests that shock repetition might be a salient factor in developing the capacity to manage resilience. Yet, as described above, it was difficult to find the boundaries between absorptive, adaptive and transformative capacities for repeated shocks. When could transformative capacity shift to adaptive? What accumulation of factors creates such a change? Future evolutions of the framework may wish to address such questions.

\section{CONCLUSIONS}

The community displayed the capacity to absorb and adapt when managing their health needs after floods, substantially relieving the burden on the health system to respond to floods. However, power dynamics and limited support may be creating the need for more capacity, putting their capacities and the health systems at risk to different kinds of shocks. Acknowledging the role of the community in managing health needs during floods could help direct health services in the public health system and may grant greater capacity for adapting and transforming processes to strengthen health system resilience.

Acknowledgements The authors would like to thank all the women and men who took part in this study. The authors would also like to thank the second data collector for her exceptional work during data collection, Sophea Men for her translation of the transcripts, Dr Mathilde Sengoelge for her comments on the manuscript and Vannarath Te for his important contributions during piloting.

Contributors DDS, PI, CH, HM-A and JVS designed the study. DDS, HH and DT collected the data. HM-A took part in the piloting. DDS led the data analysis and wrote the manuscript with input from all coauthors. All authors agreed on the final version of the manuscript.

Funding The study was funded by a grant from the Swedish Research Council (2016-05678).

\section{Competing interests None declared.}

Patient and public involvement Patients and/or the public were not involved in the design, conduct, reporting or dissemination plans of this research.

\section{Patient consent for publication Not required.}

Ethics approval The study was approved by the National Ethics Committee for Health Research in Cambodia (204and 276 NECHR) and the Swedish Ethical Review Authority (Dnr: 2019-02458) and followed the principles of the Declaration of Helsinki.

Provenance and peer review Not commissioned; externally peer reviewed.

Data availability statement No data are available. This is a qualitative study of a small, specific population in two unique geographic regions of rural Cambodia. 
Making the full data set publicly available could potentially breach the privacy that was promised to participants when they agreed to take part and the ethics approval granted from the National Ethics Committee for Human Research in Cambodia and the Swedish Ethical Review Authority. Therefore, the authors will not make the full transcripts available to a wider audience.

Open access This is an open access article distributed in accordance with the Creative Commons Attribution Non Commercial (CC BY-NC 4.0) license, which permits others to distribute, remix, adapt, build upon this work non-commercially, and license their derivative works on different terms, provided the original work is properly cited, appropriate credit is given, any changes made indicated, and the use is non-commercial. See: http://creativecommons.org/licenses/by-nc/4.0/.

\section{ORCID iDs}

Dell D Saulnier http://orcid.org/0000-0001-7761-0737

Claudia Hanson http://orcid.org/0000-0001-8066-7873

\section{REFERENCES}

1 Centre for Research on the Epidemiology of Disasters. Natural disasters 2018. Brussels: CRED, 2019.

2 IPCC. Global warming of $1.5^{\circ} \mathrm{C}$ : an IPCC special report on the impacts of global warming of $1.5^{\circ} \mathrm{C}$ above pre-industrial levels and related global greenhouse gas emission pathways, in the context of strengthening the global response to the threat of climate change, sustainable development, and efforts to eradicate poverty. Geneva: World Meteorological Organization, 2018.

3 UNISDR. Making development sustainable: the future of disaster risk management. global assessment report on disaster risk reduction. Geneva: UNISDR, 2015

4 Kruk ME, Myers M, Varpilah ST, et al. What is a resilient health system? lessons from Ebola. Lancet 2015;385:1910-2.

5 Hanefeld J, Mayhew S, Legido-Quigley $\mathrm{H}$, et al. Towards an understanding of resilience: responding to health systems shocks. Health Policy Plan 2018;33:355-67.

6 Barasa E, Mbau R, Gilson L. What is resilience and how can it be Nurtured? A systematic review of empirical literature on organizational resilience. Int J Health Policy Manag 2018;7:491-503.

7 Curtis S, Fair A, Wistow J, et al. Impact of extreme weather events and climate change for health and social care systems. Environ Health 2017;16:128.

8 Whitmee S, Haines A, Beyrer C, et al. Safeguarding human health in the Anthropocene epoch: report of the Rockefelle Foundation-Lancet Commission on planetary health. Lancet 2015;386:1973-2028.

9 Jakubicka T, Vos F, Phalkey R, et al. Health impacts of floods in Europe: data gaps and information needs from a spatial perspective. Heidelberg and Brussels: Universitätsklinikum and CRED, 2010.

10 Blanchet K, Nam SL, Ramalingam B, et al. Governance and capacity to manage resilience of health systems: towards a new conceptual framework. Int J Health Policy Manag 2017;6:431-5.

11 Thomas S, Keegan C, Barry S, et al. A framework for assessing health system resilience in an economic crisis: Ireland as a test case. BMC Health Serv Res 2013;13:450.

12 Barasa EW, Cloete K, Gilson L. From Bouncing back, to nurturing emergence: reframing the concept of resilience in health systems strengthening. Health Policy Plan 2017;32:iii91-4.

13 OECD. Guidelines for resilience systems analysis. OECD, 2014

14 Kutzin J, Sparkes SP. Health systems strengthening, universal health coverage, health security and resilience. Bull World Health Organ 2016;94:2.

15 Abimbola S, Topp SM. Adaptation with robustness: the case for clarity on the use of 'resilience' in health systems and global health. BMJ Glob Health 2018;3:e000758.

16 Abimbola S, Negin J, Martiniuk AL, et al. Institutional analysis of health system governance. Health Policy Plan 2017;32:1337-44.

17 Olmen JV, Criel B, Bhojani U, et al. The health system dynamics framework: the introduction of an analytical model for health system analysis and its application to two case-studies. Hcs 2012;2:1-21.

18 Kittelsen SK, Keating VC. Rational trust in resilient health systems. Health Policy Plan 2019;34:553-7.

19 Gilson L. Trust and the development of health care as a social institution. Soc Sci Med 2003;56:1453-68.

20 Martineau T, McPake B, Theobald S, et al. Leaving no one behind: lessons on rebuilding health systems in conflict- and crisis-affected states. BMJ Glob Health 2017;2:e000327.

21 Martineau FP. People-centred health systems: building more resilient health systems in the wake of the Ebola crisis. Int Health 2016;8:307-9.
22 Kieny MP, Dovlo D. Beyond Ebola: a new agenda for resilient health systems. Lancet 2015;385:91-2.

23 Turenne CP, Gautier L, Degroote S, et al. Conceptual analysis of health systems resilience: a scoping review. Soc Sci Med 2019;232:168-80.

24 Peters DH. Health policy and systems research: the future of the field. Health Res Policy Syst 2018;16:84.

25 Wilkinson A, Parker M, Martineau F, et al. Engaging 'communities': anthropological insights from the West African Ebola epidemic. Philos Trans R Soc Lond B Biol Sci 2017;372:pii20160305:20160305.

26 Sochas L, Channon AA, Nam S. Counting indirect crisis-related deaths in the context of a low-resilience health system: the case of maternal and neonatal health during the Ebola epidemic in Sierra Leone. Health Policy Plan 2017;32:iii32-9.

27 Kruk ME, Kujawski S, Moyer CA, et al. Next generation maternal health: external shocks and health-system innovations. Lancet 2016;388:2296-306

28 Saulnier DD, Hom H, Thol D. Generating knowledge on health systems resilience: a qualitative study of health worker perspectives on antenatal and childbirth services during floods in Cambodia, 2020.

29 National Institute of Statistics Cambodia. Cambodia inter-censal population survey 2013. Phnom Penh: Ministry of Planning, 2013.

30 World Bank. Where have all the poor gone? Cambodia poverty assessment 2013. Washington, D.C: World Bank, 2014.

31 World Bank. World DataBank. Available: http://databank.worldbank. org/data/home.aspx [Accessed Oct 2019].

32 Mekong River Commission. Annual Mekong flood report 2014. Vientiane: Mekong River Commission, 2015.

33 Mekong River Commission. The study on the sustainable management and development of the Mekong River Basin, including impacts of mainstream hydropower projects: flood sector key findings report. Vientiane and Phnom Penh: Mekong River Commission, 2018.

34 ACAPs. Secondary data review: Cambodia. Geneva: ACAPs, 2011.

35 Reliefweb. Disasters: Cambodia. Available: https://reliefweb.int/ disasters? country=48\#content [Accessed Sep 2019].

36 Andersen H, Larsson K-A, Öjendal J. Supporting state-building for democratisation? A study of 20 years of Swedish democracy aid to Cambodia. Rapport. 03. Stockholm: Expertgruppen för biståndsanalys, 2019.

37 Ledgerwood J. Buddhist ritual and the reordering of social relations in Cambodia. South East Asia Research 2012;20:191-205.

38 Kelsall T, Heng S. Inclusive healthcare and the political settlement in Cambodia. New Political Economy 2016;21:238-55.

39 Ministry of Health Cambodia. Guidelines on minimum package of activities for health center development 2008-2015. Phnom Penh: Ministry of Health, 2007.

40 Ministry of Health Cambodia. National guidelines on complementary package of activities for referral hospital development from 2006 to 2010. Phnom Penh: Ministry of Health, 2006.

41 Ministry of Health Cambodia. Community participation policy for health. Phnom Penh: Ministry of Health, 2008.

42 Saulnier DD, Hanson C, Ir P, et al. The effect of seasonal flooding on health: analysis of six years of health data in a flood-prone setting. Int J Environ Res Public Health 2018;15:pii:E656.

43 Pol S, Fox-Lewis S, Neou L, et al. If you come from a well-known organisation, I will trust you: Exploring and understanding the community's attitudes towards healthcare research in Cambodia. PLoS One 2018;13:e01952511.

44 Malterud K, Siersma VD, Guassora AD. Sample size in qualitative interview studies: guided by information power. Qual Health Res 2016;26:1753-60.

45 Braun V, Clarke V. Using thematic analysis in psychology. Qual Res Psychol 2006;3:77-101.

46 van de Pas R, Ashour M, Kapilashrami A, et al. Interrogating resilience in health systems development. Health Policy Plan 2017;32:iii88-90.

47 Ministry of Health Cambodia. National strategy for reproductive and sexual health in Cambodia: 2012-2016. Phnom Penh: Ministry of Health, 2012.

48 Alameddine M, Fouad FM, Diaconu K, et al. Resilience capacities of health systems: accommodating the needs of Palestinian refugees from Syria. Soc Sci Med 2019;220:22-30.

49 DFID. Defining disaster resilience: a DFID approach paper. London: DFID, 2011

50 Pendall R, Foster KA, Cowell M. Resilience and regions: Building understanding of the metaphor. Cambridge Journal of Regions. Economy and Society 2009;3:71-84. 
51 Liverani M, Nguon C, Sok R, et al. Improving access to health care amongst vulnerable populations: a qualitative study of village malaria workers in Kampot, Cambodia. BMC Health Serv Res 2017;17:335.

52 Gilson L. Editorial: building trust and value in health systems in lowand middle-income countries. Soc Sci Med 2005;61:1381-4.

53 Ir P, Korachais $\mathrm{C}$, Chheng $\mathrm{K}$, et al. Boosting facility deliveries with results-based financing: a mixed-methods evaluation of the government midwifery incentive scheme in Cambodia. BMC Pregnancy Childbirth 2015;15:170.

54 Page W, Murray L, Phun K, et al. Patient narratives of illnesses requiring abdominal surgery in Cambodia: Heroic/stoic, and dealing with 'the ball of meat'. Glob Public Health 2019;3:1-13.

55 Gryseels C, Kuijpers LMF, Jacobs J, et al. When 'substandard' is the standard, who decides what is appropriate? Exploring healthcare provision in Cambodia. Crit Public Health 2019;29:460-72.

56 Ith P, Dawson A, Homer CSE. Women's perspective of maternity care in Cambodia. Women Birth 2013;26:71-5.

57 Ahmed SM, Rawal LB, Chowdhury SA, et al. Cross-country analysis of strategies for achieving progress towards global goals for women's and children's health. Bull World Health Organ 2016;94:351-61.

58 Annear PL, Grundy J, Ir P, et al. The Kingdom of Cambodia health system review. Geneva: Asia Pacific Observatory on Public Health Systems and Policies, 2015.

59 Jacobs B, Men C, Bigdeli M, et al. Limited understanding, limited services, limited resources: patients' experiences with managing hypertension and diabetes in Cambodia. BMJ Glob Health 2017;2:e000235.

60 National Institute of Statistics, Directorate General for Health, Icf international. Cambodia demographic and health survey 2014. Phnom Penh and Rockville, Maryland: National Institutet of Statistics, Directorate General for Health, and ICF International, 2015.

61 Jacobs B, Bajracharya A, Saha J, et al. Making free public healthcare attractive: optimizing health equity funds in Cambodia. Int J Equity Health 2018;17:88. 